\title{
Elusive diagnosis of lymphadenopathy in a young woman
}

\author{
Cristina Peña Arce, ${ }_{1}^{1}$ Oscar Vazquez-Gomez, ${ }_{1}^{1}$ Rafael García Carretero, ${ }^{1}$ \\ Cristina Diego Hernandez ${ }^{2}$
}

'Internal Medicine, Mostoles University Hospital, Mostoles, Madrid, Spain

${ }^{2}$ Department of Pathology, Mostoles University Hospital, Mostoles, Madrid, Spain

\section{Correspondence to}

Dr Cristina Peña Arce, cristinapenarce@icloud.com

Accepted 24 May 2019

\section{DESCRIPTION}

A 30-year-old woman, treated with immunomodulators due to an ulcerative colitis, presented to our hospital with an accidental finding of bilateral axillary polyadenopathies on echography in a presurgery breast augmentation procedure. The patient claimed no symptoms, and the fact that she lived with cats was the only epidemiological data of interest. A physical examination revealed painless and superficial adenopathies approximately $1 \mathrm{~cm}$ large on both the left supraclavicular fossa and bilateral axillary cavity. Three tattoos were found on the patient (figure 1).

Several laboratory tests were performed with the following results: CRP $11.8 \mathrm{mg} / \mathrm{L}$ and ESR $25 \mathrm{~mm} / \mathrm{h}$, with autoimmunity, serologies (HBV, HCV, HIV, CMV, EBV, toxoplasma, syphilis and Bartonella henselae) and IGRA tests all negative. A thoracoabdominal CT confirmed the subcentimetric adenopathies (left supraclavicular and bilateral axillary), which suggested lymphocyte proliferation disorder as the most likely diagnosis. Positron emission tomography revealed multiple hypermetabolic adenopathies with low uptake, so low-grade lymphoproliferative syndrome could not be ruled out (figure 1).

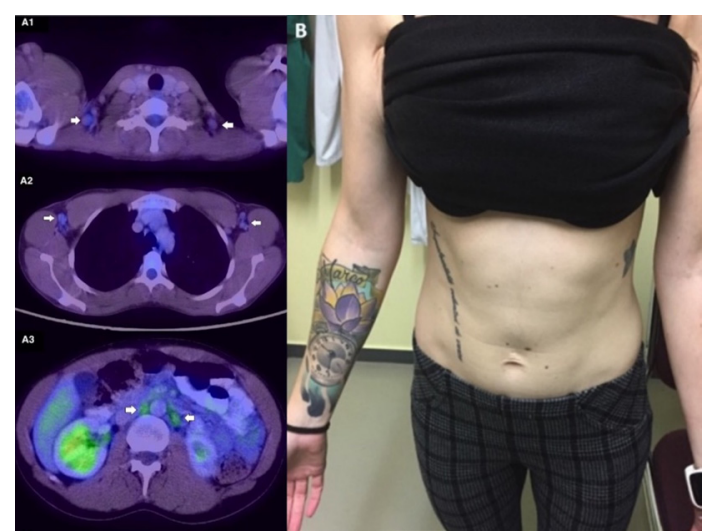

Figure 1 Positron emission tomography (A) Hypermetabolic adenopathies with low uptake at both the supradiaphragmatic and infradiaphragmatic levels. Several bilateral laterocervical adenopathies, with those at the supraclavicular level being larger (SUVmax: 0.98), and all in both axillary cavities with low uptake (A1-A2). Enhanced uptake of 18F-fluorodeoxyglucose (SUVmax: 1.63) was observed in retroperitoneal regions (A3). The patient (B) with large decorative tattoos on her right forearm, right hemiabdomen and left hypochondrium.

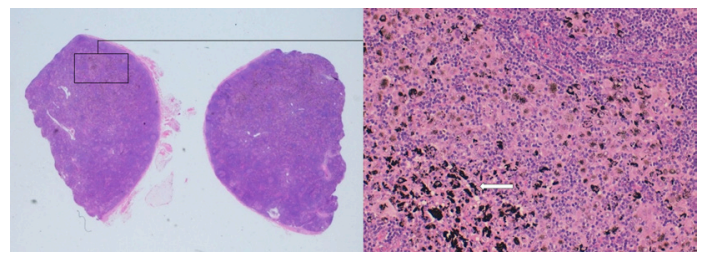

Figure 2 Ganglionic biopsy. Lymph node with sinusoidal distension and epithelioid histiocytes, containing exogenous dark material compatible with the pigments in the tattoos.

Given the lack of a definitive diagnosis, the fact that low levels of FDG uptake cannot completely dismiss malignancy, the use of immunosuppressive therapies, and the emotional distress showed by the patient, we asked the surgery department to perform an exeresis of the most accessible one (the left supraclavicular). Its dark colour caught their attention. Once the sample was processed, the department of pathology asked whether the patient had any tattoos.

A diagnosis of pigment-related lymphadenopathy was made (figure 2).

Our aim with this case is to draw attention to the potential adverse effects of having tattoos. This aesthetic procedure is more and more common in our society (about 60 million people in Europe and 16\% of the population in the USA have at least one tattoo). ${ }^{1}$ However, there is widespread lack of knowledge regarding how ink degrades under the skin as well as the effects of such degradation. The biggest problem may arise over the long term, as some patients have had reactions months or years following the procedure (it was 6 years in the case of our patient).

Pigment accumulates in the dermis and spreads across the intracellular space, causing haemorrhage, necrosis and inflammation that results in phagocytosis by skin macrophages. Macrophages reach the lymph nodes, where inflammatory reactions can take place and, in many cases, last long after the tattoo has been removed. Sometimes this can be revealed subclinically (autopsies of tattooed patients sometimes reveal the existence of regional adenopathies with pigments). ${ }^{1}$

In some cases, malignant skin tumours may develop within the tattoos. The pigments used can degrade with exposure to light, releasing potentially carcinogenic substances via haematogenous spread. ${ }^{2}$ It can be difficult to differentiate a neoplastic process from pigment-related lymphadenopathy (in tattooed oncological patients can be mistaken as neoplastic progression). PET/ CT can help to avoid unnecessary biopsies. The 
results were doubtful in the case of our patient, although false positives have been described. ${ }^{3}$ Histological confirmation can be necessary under such circumstances. Our differential diagnosis was established with a lymphocyte proliferation, and the final diagnosis was anatomopathological.

\section{Learning points}

Pigment lymphadenopathy must be part of the differential diagnosis for tattooed patients with adenopathies of unknown aetiology in draining lymph nodes.

- Even though positron emission tomography/CT can produce false-positives, its proper interpretation must be carefully considered to avoid unnecessary exploration.

- A histological diagnosis is not necessary in every patient, but in the event of doubt a differential diagnosis of malignant entities must always be histological.
Contributors CPA: discuss planning, reporting, follow-up of the case, conception and design, acquisition of informed consent, writing the case and cover letter. OV-G: discuss planning, reporting, follow-up of the case and writing the case. RGC: discuss planning, reporting, follow-up of the case. CDH: discuss planning, follow-up of the case, anatomopathological analysts and take the pictures.

Funding The authors have not declared a specific grant for this research from any funding agency in the public, commercial or not-for-profit sectors.

Competing interests None declared.

Patient consent for publication Obtained.

Provenance and peer review Not commissioned; externally peer reviewed.

\section{REFERENCES}

1 Bordea C, Latifaj B, Jaffe W. Delayed presentation of tattoo lymphadenopathy mimicking malignant melanoma lymphadenopathy. J Plast Reconstr Aesthet Surg 2009;62:e283-e285.

2 Laux P, Tralau T, Tentschert J, et al. A medical-toxicological view of tattooing. Lancet 2016;387:395-402.

3 Fukumoto Y, Sugimoto S, Okada M, et al. False-positive axillary lymph node on positron emission tomography/computed tomography in a thymoma patient with a tattoo. Eur $J$ Cardiothorac Surg 2015;48:804.

Copyright 2019 BMJ Publishing Group. All rights reserved. For permission to reuse any of this content visit https://www.bmj.com/company/products-services/rights-and-licensing/permissions/

BMJ Case Report Fellows may re-use this article for personal use and teaching without any further permission

Become a Fellow of BMJ Case Reports today and you can:

- Submit as many cases as you like

- Enjoy fast sympathetic peer review and rapid publication of accepted articles

- Access all the published articles

- Re-use any of the published material for personal use and teaching without further permission

\section{Customer Service}

If you have any further queries about your subscription, please contact our customer services team on +44 (0) 2071111105 or via email at support@bmj.com.

Visit casereports.bmj.com for more articles like this and to become a Fellow 